\title{
ESTUDO DA SITUAÇÃO DO SANEAMENTO BÁSICO EM TIMBÓ GRANDE
}

Kelvin José Nunes de Souza ${ }^{1}$

Luciane Dusi

\section{RESUMO}

Este trabalho apresenta a importância do saneamento básico para a saúde pública. Suas esferas são - tratamento de água, tratamento de esgoto, coleta e destinação do resíduos sólidos e drenagem urbana. Estas fazem com que se viva bem e com qualidade de vida. Todas as cidades necessitam destes serviços, com base nisso o presente trabalho nos trará a situação do saneamento básico no município de Timbó Grande -SC, apresentando o Plano Municipal de Saneamento Básico e algumas de suas metas para o bom andamento das quatro esferas.

Palavras-Chave: Saneamento Básico. Tratamento de Água. Tratamento de Esgoto, Resíduos Sólidos. Drenagem Urbana.

\section{ABSTRACT}

This paper presents the importance of basic sanitation for public health. Its spheres are - water treatment, sewage treatment, collection and disposal of solid waste and urban drainage. These make you live well and quality of life. All cities need these services, based on this the present work will bring us the basic sanitation situation in the municipality of Timbó Grande-SC, presenting the Municipal Sanitation Basic Plan and some of its goals for the progress of the four spheres.

Keywords: Basic Sanitation. Water Treatment. Sewage Treatment. Solid Waste. UrbanDrainage.

\footnotetext{
${ }^{1}$ Acadêmico do Curso de Engenharia Civil da Universidade Alto Vale do Rio do Peixe (UNIARP).

2 Mestre em Engenharia Sanitária Ambiental pela Universidade Federal de Santa Catarina (UFSC). Docente do Curso de Engenharia Civil da Universidade Alto Vale do Rio do Peixe (UNIARP). Email:dusiluciane@gmail.com.
} 


\section{INTRODUÇÃO}

O presente trabalho trata sobre a importancia do saneamento básico e qual a situação no municipio de Timbó Grande- SC.

O Saneamento básico é imprescindível nos lugares habitados para a sobrevivência e bem estar social. Composto pelas quatro esferas, sendo: águas de abastecimento público, esgotamento sanitário, resíduos sólidos e drenagem urbana, são elas o mínimo que uma cidade precisa para que a vida não pereça (PORTAL SANEAMENTO BÁSICO, 2017).

De forma geral, pode-se dizer que o saneamento caracteriza o conjunto de ações socioeconômicas que tem objetivo de alcançar salubridade ambiental.

Entende-se por salubridade ambiental, o estado de higidez (estado normal de saúde) em que a população urbana e rural vivem, tanto no que refere-se a sua capacidade de prevenir, inibir ou impedir a ocorrência de epidemias ou endemias veiculadas pelo meio ambiente, quanto no tocante ao seu potencial de promover o aperfeiçoamento de condições mesológicas (que diz respeito ao clima ou ambiente) favoráveis ao pleno gozo de saúde e bem estar (GUIMARÃES; CARVALHO; SILVA, 2017).

O objetivo geral deste trabalho é relatar as condições atuais das quatro esferas de saneamento no município de Timbó Grande, tendo como objetivos especificos: elaborar uma pesquisa bibliográfica sobre saneamento básico (TCC I), Apresentar o Plano Municipal de saneamento básico de Timbó Grande, elaborar relatório final do levantamento, obtendo uma visão geral da situação em Timbó Grande em relação ao saneamento básico.

\section{DESENVOLVIMENTO}

Nessa parte do trabalho serão apresentados os conceitos mais importantes a respeito do saneameto básico, bem como material a serem empregados para se alcançar os objetivos, e por fim os resultados.

\subsection{SANEAMENTO BÁSICO}

Sanear vem do latim sanu: tornar saudável, tornar habitável, higienizar 
(ORIGEM DA PALAVRA, 2017; GLOSBE, 2017).

Desde as mais antigas civilizações, o ser humano não vive distante da água que bebe e dos seus resíduos gerados.

Por mais que o ser humano com o passar dos anos, tenha aprimorado várias técnicas de coletar a água e de afastar-se dos detritos, este problema persiste ao os nossos dias atuais (DACACH, 1990).

Pode-se considerar Saneamento, um conjunto de medidas, principalmente relacionadas ao solo, à agua, ao ar, à habitação e aos alimentos nas quais se destacam a ação do Engenheiro, visando quebrar elos das cadeias de transmissão das doenças (DACACH, 1990).

Para a Organização Mundial de Saúde (OMS) é de modo geral, o controle de todos os fatores do meio físico do homem que geram um efeito deletério sobre seu bem estar físico, mental ou social (DACACH, 1990).

Ainda segundo Dacach (1990), Saneamento básico busca preservar a saúde das pessoas, melhorando-lhes as condições sanitário do meio ambiente.

Para Costa (1999), Saneamento básico resume-se no aglomerado de ações interpostas pelo setor de saúde, direcionadas à sua defesa e proteção, com a ideia de construir ou reconstruir a vida na sociedade, priorizando a qualidade de vida. As atividade de Saneamento básico definem-se ao aprovisionamento de água potável, à coleta e destinação final dos resíduos sólidos e ao tratamento de efluentes.

De acordo com a Lei Federal 11.445 (BRASIL, 2007), definem-se como serviços públicos de Saneamento básico: Abastecimento de água, esgotamento sanitário, limpeza urbana e manejo dos resíduos sólidos, drenagem e manejo de água pluviais.

O Saneamento básico torna-se fundamental para o desenvolvimento sustentável. Seu papel é garantir o equilíbrio do bem estar da sociedade com as questões de preservação ambiental (FUNASA, 2006).

\subsubsection{Problemas Causados Pela Falta de Saneamento Básico}

O principal problema pela falta de saneamento é a grande ameaça à saúde pública. Uma parcela gigantesca da população que não recebe este serviço básico, está perigosamente suscetível a várias doenças causadas pelas péssimas condições 
oriundas da falta de tratamento de água e esgoto. A exposição a bactérias, vírus e condições insalubres aumenta a incidência de doenças (PORTAL SANEAMENTO BÁSICO, 2017).

Por afetarem diretamente a população e o meio em que vivem, a falta de saneamento acarretam em vários problemas e devem ser tratados com urgência. Para Luz (2005), algumas soluções podem ser tomadas para solucionar os problemas na poluição das águas: rigorosas leis que obriguem as industrias a tratar seus resíduos para depois lança-los no meio ambiente; industrias em descumprimento da lei, severas penalizações ou até o fechamento se as mesmas forem reincidentes; aumentar as áreas de fiscalização destas indústrias; ampliar as instalações de rede de esgoto; Saneamento básico como responsabilidade do estado; melhoramento e investimento no sistema de coleta e separação do lixo; entre outras. Segundo Segreti e Bito (2006), o governo deve criar legislações rigorosas e projetos voltados a obrigação dos países para reduzir a produção e lançamento de gases e como na falta de saneamento os gases também são gerados de forma sem controle, como consequência haverá uma melhoria na condição de saneamento.

\subsubsection{Lei 11.445}

A Lei 11.445/07 Lei Federal do Saneamento Básico, aborda o conjunto completo de serviços de abastecimento público de água potável, coleta, tratamento e disposição final adequada dos esgotos sanitários; drenagem e manejo da aguas pluviais urbanos, além da limpeza das cidades e do manejo dos resíduos sólidos (PORTAL RESÍDUOS SÓLIDOS, 2017).

Esta lei foi concebida de maneira a dar abrigo a todas as formas dentro da legalidade possíveis de organização institucional para os serviços de saneamento básico, havendo coerência com as realidades sociais múltiplas, econômicas e ambientais do Brasil (MINISTÉRIO DAS CIDADES, 2017).

\subsubsection{As Quatro Esferas do Saneamento}

São elas - tratamento de água, tratamento de esgoto, coleta e destinação dos resíduos sólidos e drenagem urbana. 


\subsubsection{Tratamento de água}

A água doce como é conhecida, é um recurso finito, e as quantidades suprimidas acessíveis estão se tornando menos abundantes. O aumento da população e da renda e as mudanças climáticas devem exacerbar a questão da escassez de água que já é uma realidade em várias partes do mundo. Encontrar soluções que sejam sustentáveis são dificultadas pelas demandas energéticas para se obter, armazenar, produzir uma água segura, fabricar o produto químico e o material usado em todo o processo de fornecimento e bombeá-la. A medida que a sociedade usa fontes menos desejáveis de água para atender à demanda crescente, a quantidade de energia incorporada em todo nosso abastecimento de água deve aumentar. Consequentemente, existe a necessidade de se desenvolverem inovadoras estratégias de gerenciamento da água para que se atenda a demanda global por uma água potável segura (MIHELCIC; ZIMMERMAN; 2015).

Segundo Barros (1995), o tratamento e sistema de abastecimento de água representa um conjunto de obras, equipamentos e serviços destinados ao abastecimento de água potável para fins de consumo doméstico, serviços públicos, consumo industrial e outros usos.

A água é um recurso natural com inúmeros usos. "Além disso, ela é essencial à vida humano e ao funcionamento dos ecossistemas" (BRAGA, 2008, p.17).

Tendo como objetivo, o tratamento da água é fornecer água potável que seja palatável. A água potável é a água saudável para o consumo humano, livre de compostos orgânicos e inorgânicos e de microrganismo danosos que causam efeitos fisiológicos adversos ou tenham sabor ruim. O termo palatável, descreve a água que é esteticamente aceita para beber ou que é livre de turpidez, de cor, de odor, e de gosto desagradável. Assim, a água palatável pode não ser segura (MIHELCIC; ZIMMERMAN; 2015). 


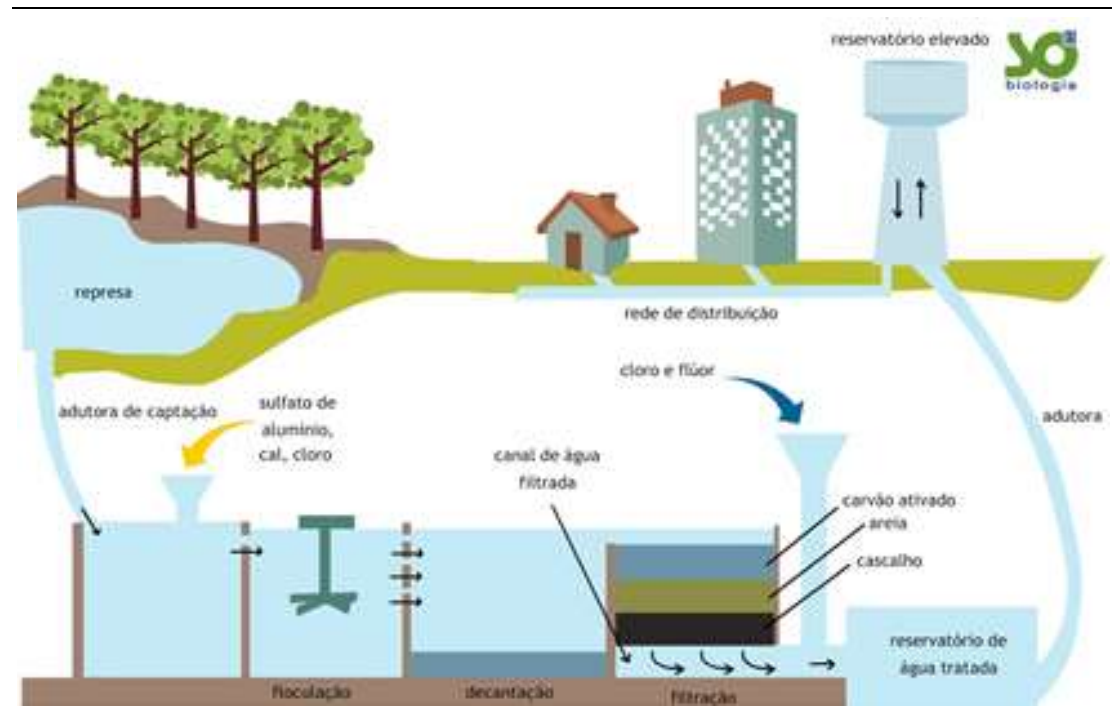

Fonte: SO BIOLOGIA, 2017

\subsubsection{Tratamento de esgoto}

Define-se como tal, um conjunto de elementos os quais tem por objetivo a coleta, o transporte, o tratamento e a disposição final do esgoto (Crespo, 1997).

Como resultado da evolução humana, surgem os sistemas de tratamento de esgoto, essencial para sobrevivência. Para Jordão; e Pessoa; (1995) a água tem fator primordial na formação de novas comunidades e na fixação do homem. O ser humano sempre buscou se fixar nas regiões em que possa saciar suas necessidades básicas: água, alimento e calor. Por conta desta incansável busca de nossos ancestrais, se chegou a situação atual: elevadas densidades populacionais, próximos a rios e nascentes.

De acordo com a NBR 9.648 (Associação Brasileira de Normas Técnicas ABNT, 1986, p. 1): "[...] esgoto sanitário é o despejo liquido constituído de esgotos doméstico e industrial, água de infiltração e a contribuição pluvial parasitária".

Ainda com base nesta mesma norma, esgoto doméstico é o despejo líquido resultante pelo uso da água para a higiene pessoal e necessidades fisiológicas humanas; esgoto industrial fica definido como o despejo líquido resultante dos processos industriais, tendo este que respeitar os padrões de lançamento estabelecidos; água de infiltração é considerada toda água proveniente do subsolo, não desejável para o sistema separador e que adentra nas canalizações; contribuição 
pluvial parasitária é uma parcela do escoamento superficial inevitavelmente absorvida pela rede coletora de esgoto sanitário.

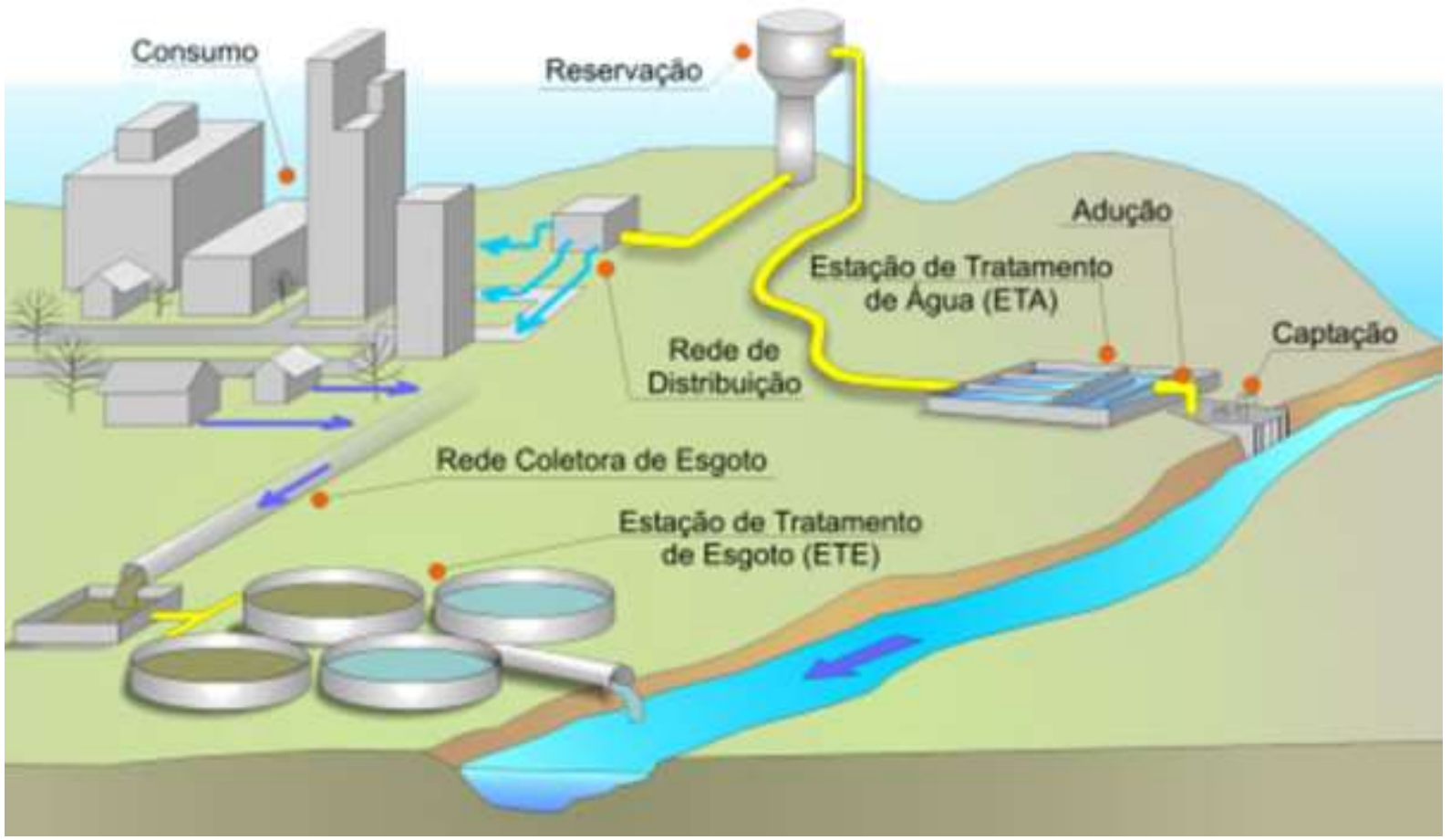

Fonte: UNIAGUÁS, 2017

\subsubsection{Coleta e destinação dos resíduos sólidos}

Os resíduos sólidos apresentam grande complexidade e diversidade. Suas características físicas, químicas e biológicas podem variar de acordo com sua fonte ou atividade geradora. Fatores, sociais, econômicos, geográficos, culturais, educacionais, tecnológicos e legais afetam o processo de geração dos resíduos sólidos, tanto a sua composição qualitativa quanto em ralação à quantidade gerada. Uma vez que o resíduo solido é gerado, a forma como é manejado, tratado e destinado pode alterar suas características de forma, que em certos casos, os riscos ao ambiente e a saúde são potencializados (CASTILHOS JUNIOR, 2006).

A NBR 10.004 (ABNT, 2004, p 01) define os Resíduos sólidos como:

Resíduos nos estados sólidos e semi-sólido, que resultam de atividade de origem industrial, domestica, hospitalar, comercial, agrícola, de serviços e de varrição. Ficam incluídos nesta definição os lodos provenientes de 
sistemas de tratamento de água, aqueles gerados em equipamentos e instalações de controle de poluição, bem como determinados líquidos cujas particularidades tornem inviável o seu lançamento na rede pública de esgotos ou corpos de agua, ou exijam para isso soluções, técnicas e economicamente, inviáveis em face a melhor tecnologia disponível.

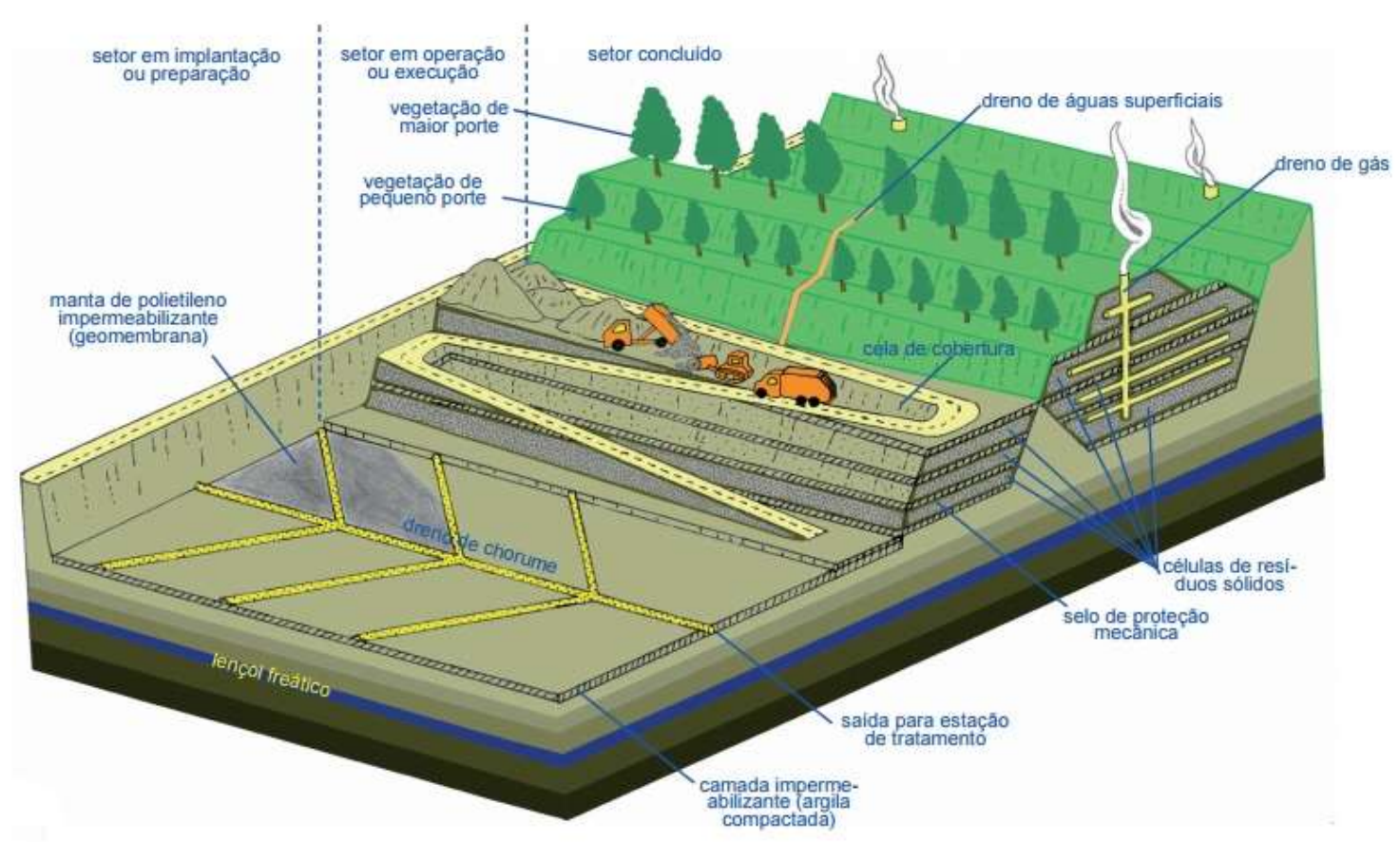

Fonte: SANTAELLA et al., 2014.

\subsubsection{Drenagem urbana}

A drenagem urbana, sendo uma esfera do saneamento, também contempla-se na Lei № 11.445/2007, que visa a possibilidade de aplicação da drenagem em todas as áreas urbanas, como complementação a serviços adequados à saúde pública, segurança da vida e de patrimônios públicos e privados. Nesta mesma lei, a o manejo e a drenagem de águas pluviais urbanas são um conjunto de atividades, instalações operacionais e infraestrutura de drenagem urbana de águas pluviais, do transporte, retenção ou detenção para o amortecimento de vazões de cheias, tratamento e disposição final das águas drenadas nas áreas urbanas. Outro conceito, pela perspectiva de segurança em inundações, diz que projetos de 
drenagem devem escoar lentamente as águas, para evitar um aumento da vazão máxima, a frequência e o nível de inundações de jusante (TUCCI; BERTONI, 2003).

O termo drenagem urbana é compreendido como o conjunto de medidas que tenham como objetivo, minimizar os riscos relacionados a enchentes, e também diminuir os prejuízos causados por elas. Possibilitar o desenvolvimento nas áreas urbanas de forma articulada, harmônica e sustentável (TUCCl et al. 2007).

Ramos; Barros e Palos (1999), afirmam que os sistemas de drenagem urbana são classificados segundo a sua dimensão em macro e micro drenagem, que podem ser definidos da seguinte maneira:

- Macrodrenagem: são obras de maior porte, projetadas com períodos de retorno de 25 a 100 anos, são canais abertos com contorno fechado, grande galerias pluviais, dispositivos de armazenamento;

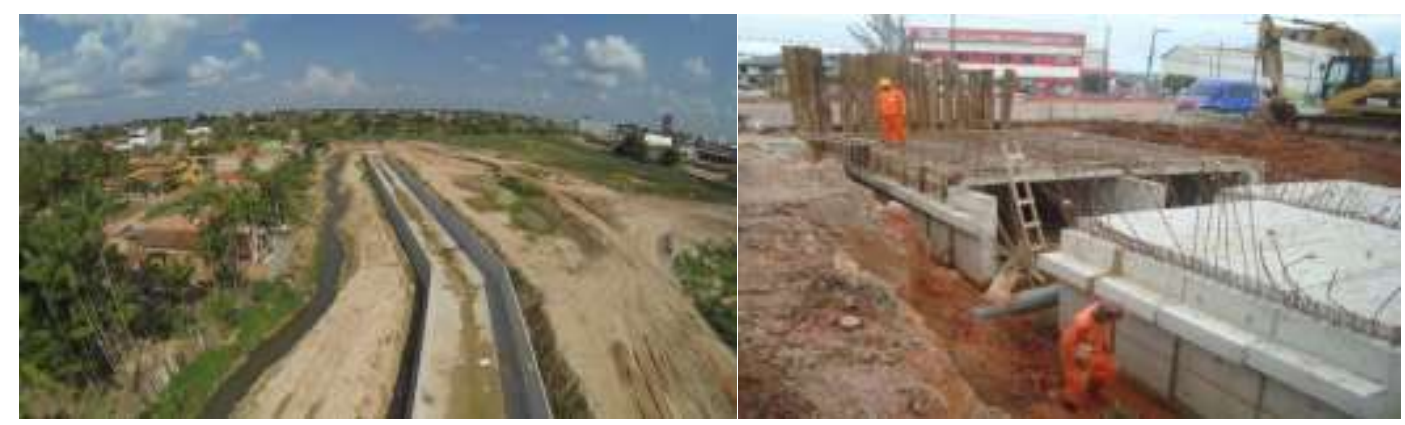

Fonte: INBRA CONSTRUTORA, 2017.

- Micro drenagem: são condutos pluviais de uma rede primária, são projetados como período de retorno de 2 a 10 anos, este normalmente é composto por:

a) Pequenas galerias, são canalizações públicas com dimensões menores que as normalmente usadas em na macro, são destinadas a conduzir o escoamento das bocas de lobo;

b) Poços de visitação são localizados ao longo dos trechos das galerias destinados a manutenção e inspeção, mudanças de direção, diâmetro e declividade.

c) Bocas de lobo: são dispositivos com a finalidade de captar as águas 
pluviais, localizados em pontos convenientes onde os greides ou as sarjetas não são suficientes para a captação do escoamento;

d) Tubos de ligação: são as tubulações destinadas a conduzir o escoamento das águas das bocas de lobo até os poços de visita ou galerias;

e) Sarjetas: são os elementos em forma de calha que tem como função, captar a água pluvial. São localizadas nas vias públicas, sendo paralelas ao meio fio.

f) Conduto forçado: é toda tubulação que opera sob pressão;

Estação de bombeamento: é o conjunto de equipamentos, sendo destinado a conduzir o escoamento, quando este for impossibilitado pela gravidade.

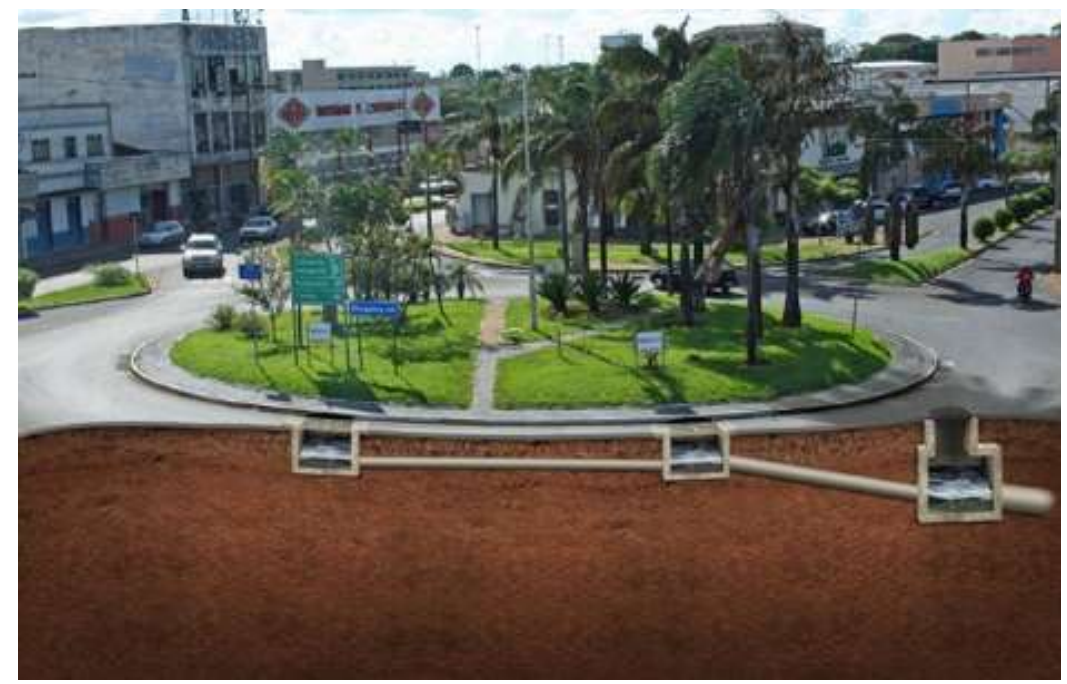

Fonte: PREFEITURA DE UBERABA, 2017

\subsubsection{Saneamento Básico no Municípo de Timbó Grande}

Sobre as quatros esferas no município.

\subsubsection{Abastecimento de água}

O Município de Timbó Grande conta com dois sistemas de abastecimento (Sistema Timbó Grande e Sistema Nossa Senhora Aparecida) operados pela CASAN 
para suprir as demandas de água para consumo humano (TIMBÓ GRANDE, 2011).

Em ambos os sistemas a água é captada em poços profundos e segue para uma estação de tratamento de água (ETA). Após passar pelo tratamento, a água segue para os reservatórios, que totalizam um volume de reservação de $175 \mathrm{~m}^{3}$ no Sistema Timbó Grande e $20 \mathrm{~m}^{3}$ no Sistema Nossa Senhora Aparecida, chegando por fim à rede de distribuição por gravidade (TIMBÓ GRANDE, 2011).

Segundo informações da CASAN, o índice médio de perdas físicas de água na distribuição (IPD) nos últimos 12 meses, foi de 25\% (TIMBÓ GRANDE, 2011).

Além destes sistemas operados pela CASAN, existem ainda mais dois sistemas de abastecimento de água: um particular, operado pela empresa Bonet Madeira e Papéis, e o outro operado pela prefeitura municipal (TIMBÓ GRANDE, 2011).

O sistema particular atende 80 ligações, sem nenhuma cobrança, na localidade de Buriti. Este sistema possui 2 reservatórios, sendo um de concreto com volume de $100 \mathrm{~m}^{3}$ e o outro de fibra de vidro com capacidade de $20 \mathrm{~m}^{3}$. O tratamento é realizado com decantação, filtração e cloração. O outro sistema existente, operado pela prefeitura, é o Sistema Cachoeira, que atende 26 famílias desta localidade (26 ligações) e possui um reservatório de fibra de $20 \mathrm{~m}^{3}$. O sistema não possui ETA e não é feita cobrança pela água, sendo que apenas os custos de manutenção são rateados entre os usuários (TIMBÓ GRANDE, 2011).

Os sistemas atendem $100 \%$ da população da área urbana e 5,7\% da população da área rural do município, resultando num índice de cobertura de água de 62,85\% da população total (TIMBÓ GRANDE, 2011).

\subsubsection{Esgotamento sanitário}

O Município de Timbó Grande não possui sistema de coleta e tratamento de esgotos, sendo que os esgotos domésticos do município são, via de regra, lançados atualmente em sistemas individuais constituídos por fossa séptica e sumidouros, e na ausência destes, encaminhados sem qualquer tratamento às galerias de águas pluviais ou diretamente aos corpos de água da região (TIMBÓ GRANDE, 2011).

A Companhia Catarinense de Águas e Saneamento - CASAN é a responsável 
pelos serviços de abastecimento de água e esgotamento sanitário em Timbó Grande. Entretanto, a Companhia não realizou, até o ano de 2010, qualquer investimento no que se refere à implantação de rede coletora e tratamento coletivo de esgoto no município (TIMBÓ GRANDE, 2011).

\subsubsection{Limpeza urbana e manejo dos resíduos sólidos}

Atualmente a prefeitura responsabiliza-se diretamente pela execução dos serviços de coleta e transporte dos resíduos sólidos urbanos (RSU) até uma central de triagem de materiais recicláveis e, posteriormente, pelo transporte dos rejeitos e dos resíduos orgânicos até a disposição final, que é feita em aterro sanitário, sob responsabilidade da Empresa ESA (Engenharia Sanitária e Ambiental), localizado no Município de Lages, a aproximadamente $160 \mathrm{~km}$ da sede municipal de Timbó Grande. A coleta convencional dos resíduos sólidos urbanos abrange 100\% da população urbana e 50\% da população rural do município (TIMBÓ GRANDE, 2011).

O município possui algumas deficiências no manejo de resíduos sólidos, principalmente no que se refere à ausência da coleta seletiva de recicláveis e de orgânicos em toda a sua extensão territorial (TIMBÓ GRANDE, 2011).

\subsubsection{Drenagem urbana e manejo das águas pluviais}

O sistema de drenagem urbana do município é composto por drenagem subterrânea do tipo separadora numa extensão aproximada de 3,5 km, captados através de bocas de lobo e caixas com grelhas na sarjeta, que encaminham as águas para cursos d'agua naturais permanentes (Rio Timbó) (TIMBÓ GRANDE, 2011).

No tocante à pavimentação e drenagem subterrânea, o município apresenta cerca de $20 \%$ de suas ruas pavimentadas, sendo que $100 \%$ destas apresentam drenagem subterrânea (TIMBÓ GRANDE, 2011).

O sistema de macro-drenagem não conta com nenhum dispositivo de detenção ou amortecimento de vazão das águas pluviais, contando somente com pontes e galerias (TIMBÓ GRANDE, 2011).

Os serviços de manutenção e conservação do sistema de drenagem são realizados pela Secretaria de Obras do município, incluindo: limpeza e desobstrução de dispositivos de captação; limpeza e desobstrução de galerias; dragagem e limpeza 
de canais; e varrição e limpeza de ruas (TIMBÓ GRANDE, 2011).

\subsubsection{Plano municipal de saneamento básico no municípo de Timbó Grande}

O Plano Municipal de Saneamento Básico (PMSB) tem como objetivo orientar o desenvolvimento das ações de governo, sendo à base de informações para os processos de tomadas de decisão e adoção de políticas públicas neste setor.

O mesmo está divido em etapas, sendo elas:

Volume I - Consolidação do Plano Municipal de Saneamento Básico;

Volume II - Processo de participação da sociedade na elaboração do plano;

Volume III - Diagnóstico da situação do saneamento e de seus impactos nas condições de vida da população;

Volume IV - Prognóstico, objetivos, metas de curto, médio e longo prazo para a universalização dos serviços de saneamento; Programas, projetos e ações necessárias para atingir os objetivos e as metas; e Ações para emergências e contingências;

Volume V - Mecanismos e procedimentos para a avaliação sistemática da eficiência e eficácia das ações programadas e participação social;

Volume VI - Elaboração do Sistema de Informações do Plano de Saneamento (TIMBÓ GRANDE, 2011).

Cada etapa, tem suas destinações e aplicações.

\subsection{METODOLOGIA E MATERIAIS}

Buscando cumprir os objetivos propostos, este presente trabalho foi dividido em duas etapas. A primeira relata a parte da revisão bibliográfica sobre o tema e a segunda trata da apresentação da situação do saneamento básico na cidade de Timbó Grande, estado de Santa Catarina, através de um estudo do plano municipal de saneamento básico, levantamentos e pesquisas nos órgãos envolvidos, verificação de campo, compilação dos resultados por meio de planilhas e gráficos e por fim um relatório apresentando a análise dos resultados. 


\subsubsection{Estudo do Plano Municipal de Saneamento Básico}

Foi feito um estudo detalhado do plano municipal de saneamento básico.

Este plano está divido em 6 volumes, após a leitura destes, foi possível identificar no "Volume IV" as informações nas quais foram construídas o trabalho.

Este Volume IV trata dos prognósticos, objetivos e metas imediatas, de curto, médio e longo prazo para a universalização dos serviços de saneamento, além de ações para emergências e contingencias.

Em todas as esferas do saneamento básico no município, foram verificados os órgãos responsáveis, levantamento de metas, qual a situação atual (executado e não executado) e a elaboração de gráficos para mensuração de resultado.

Porém, para este trabalho, foram utilizadas somente as metas imediatas e de curto prazo. Estas estipulam o que deveria e deve ser feito em cada uma das 4 esferas do saneamento básico.

\subsection{APRESENTAÇÃO, ANÁLISE DOS DADOS E RESULTADOS}

\subsubsection{Estudo do Plano Municipal de Saneamento Básico}

O presente trabalho nos traz informações sobre o Saneamento Básico no município de Timbó Grande.

Fundado em 26 de Abril de 1989, o município de Timbó Grande está localizado na microrregião de Canoinhas, na mesorregião do Norte Catarinense. Dentro da vertente do interior do Estado de Santa Catarina, a uma latitude de 2636'54" Sul e longitude de 5040’27" Oeste (TIMBÓ GRANDE, 2011).

Com área de aproximadamente $597 \mathrm{Km}^{2}$, o município encontra-se a uma altitude média de 925 metros acima do nível do mar. O principal acesso se dá pela rodovia SC-340. Os municípios limítrofes são: Bela Vista do Toldo, Calmon, Canoinhas, Irineópolis, Lebon Régis, Major Vieira, Porto União e Santa Cecília (TIMBÓ GRANDE, 2011).

Com uma população estimada em 2016 pelo Instituto Brasileiro de Geografia e Estatística - IBGE de aproximadamente 7.699 habitantes. Localizada a aproximadamente $409 \mathrm{~km}$ da capital Florianópolis, tem como atividade principal a 
extração de madeira (IBGE, CIDADES, 2017).

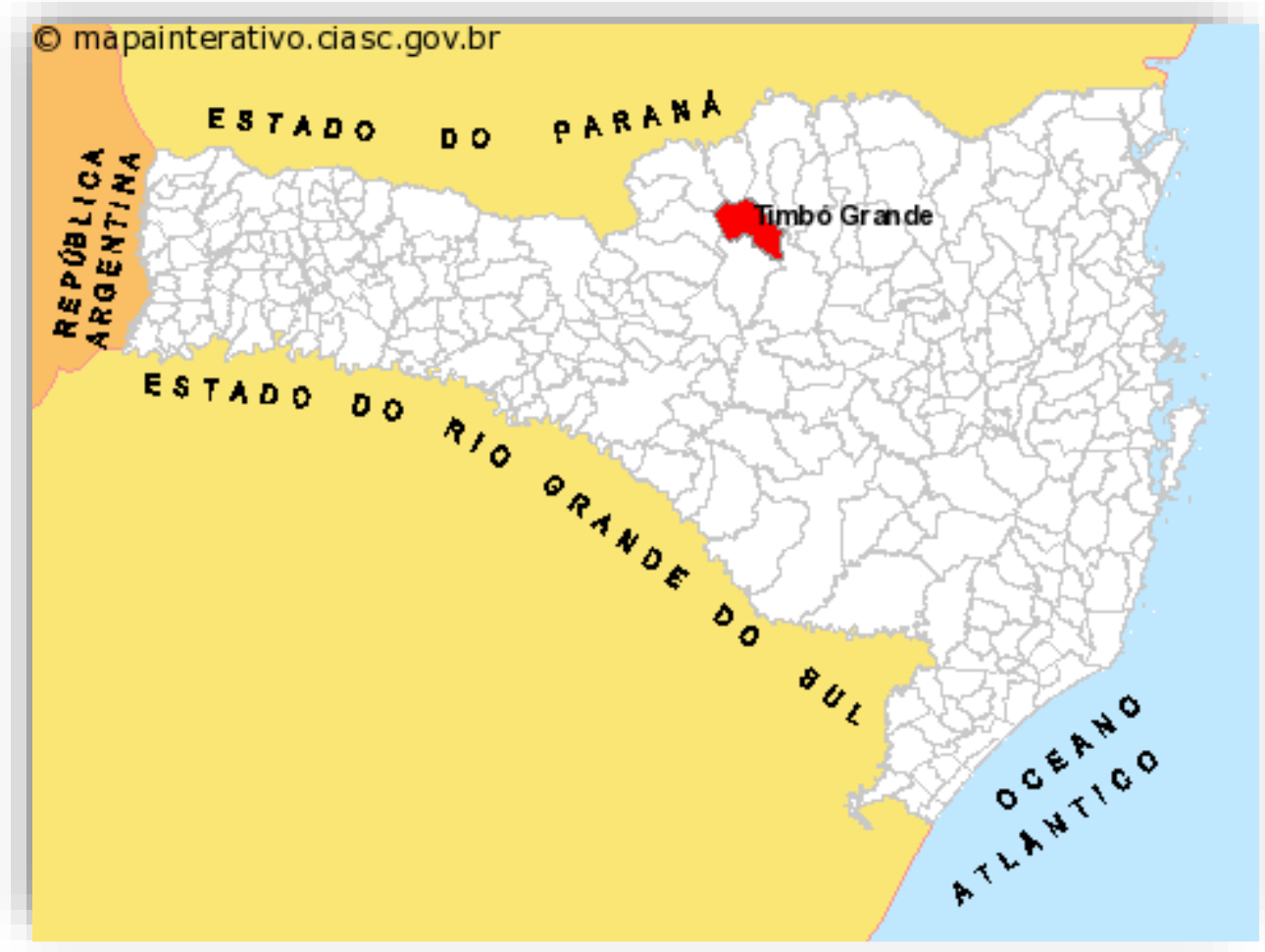

Fonte: TIMBÓ GRANDE, 2011.

\subsubsection{Situação geral}

As metas de imediato, tiveram um resultado mais conclusivo. Já as metas de curto prazo em virtude de expirarem apenas em 2019, tiveram uma interpretação menos contundente.

O que ficou notável é que o tratamento e distribuição de água, por ser responsabilidade da Casan, tem suas metas na sua maioria em andamento ou executadas. Ou seja, por se tratar de um órgão que independe da prefeitura, da documentação burocrática, e de política tem muito mais eficiência.

Para o tratamento de esgoto, a situação encontrada é precária, pois nem se quer uma fiscalização de sistemas individuais é feita, com isso, o esgoto sanitário é lançado sobre o solo e corpo receptor sem qualquer tipo de tratamento, os danos ambientais e as doenças à saúde pública são gravíssimas. 
A coleta e destinação dos resíduos sólidos é feita, mas não para todos os munícipes, esta é executada com serviços terceirizados e a disposição final vai para outra cidade. Local para triagem de materiais recicláveis está desativado juntamente com o local onde era o antigo lixão, isto de certa forma não ajuda em nada, pois os resíduos vão sem qualquer tipo de separação.

$\mathrm{Na}$ drenagem urbana, algumas ruas existem a rede, outras não. A fiscalização para que não existam esgotamento despejados na rede de forma irregular não é feita, assim, a água das chuvas juntamente com o esgoto sanitário são despejados no Rio Timbó que é o corpo receptor, com isso a contaminação do rio está acontecendo.

O tratamento de esgoto, coleta e destinação dos resíduos sólidos e drenagem urbana, são de responsabilidade da prefeitura municipal, mesmos dependem de documentação burocrática, licitações e são envolvido em políticas, a situação é grave e só terá uma melhora se as metas propostas pelo Plano Municipal de Saneamento Básico forem colocadas em práticas e executadas, pois este plano foi elaborado levando em consideração as reais necessidades para que haja um saneamento básico no município e que exista qualidade de vida.

\section{CONCLUSÃO}

Com base no estudo sobre a situação do saneamento básico no Brasil, foi analisado que tratar sobre as quatro esferas se faz necessário para evitar possíveis problemas ambientais e doenças a população. A falta destes componentes afeta e pode comprometer a saúde pública.

A prefeitura não fazer a sua parte aliada com o nível de escolaridade da população, acarreta em agravantes. Se a prefeitura mudar e executar o que precisa para o bom andamento do saneamento básico, acredita-se que a tendência seria de uma evolução no nível de melhoramento em todas as esferas comandadas por ela.

Nos documentos é tudo correto, tudo dentro do que se tem de melhor, mas a execução que fará a diferença.

Tendo em vista que esta pesquisa foi realizada com apoio do atual prefeito e atual gerente da Casan, os resultados aqui levantados servirão poderão servir de efetiva orientação para os trabalhos afetos, ao saneamento em timbó grande. 
Pois os mesmos contarão com uma visão clara e objetiva do que foi feito, do que está em andamento e do que ainda não foi iniciado em ralação a este tema na cidade.

\section{REFERÊNCIAS}

BARROS, Rafael Tobias de Vasconcelos. et al. Saneamento. Manual de saneamento e proteção ambiental para os municípios - vol. 2. Belo Horizonte: Escola de Engenharia da UFMG, 1995.

BRAGA, Benedito. P. F. Pacto federativo e gestão das águas. São Paulo: Instituto de Estudos Avançados, 2008.

BRASIL. Lei no 11.445, de 05 de janeiro de 2007. Estabelece diretrizes nacionais para o saneamento básico; altera as Leis $\mathrm{n}$ ㅇs 6.766, de 19 de dezembro de 1979, 8.036, de 11 de maio de 1990, 8.666, de 21 de junho de 1993, 8.987, de 13 de fevereiro de 1995; revoga a Lei no 6.528, de 11 de maio de 1978; e dá outras providências. Disponível em: <http://www.planalto.gov.br/ccivil_03/_ato20072010/2007/lei//11445.htm>. Acesso em: 07 mai. 2017.

CALIJURI, Maria do Carmo; CUNHA, Davi Gasparini Fernandes. Engenharia Ambiental: Conceitos, Tecnologia e Gestão. 1. ed. Rio de Janeiro: Elsevier, 2013.

CASAN. História do saneamento em Santa Catarina. Disponível em: < http://www.casan.com.br/menu-conteudo/index/url/historia-da-casan-e-dosaneamento-em-santa-catarina\#0>. Acesso em 15 de meio de 2017.

CORREA, J. Publicações oficiais do Ministério Público de Santa Catarina. Disponível em: <http://www.mp.sc.gov.br/portal/WebForms/Default.aspx >. Acesso em: 20 abr. 2017.

COSTA, Ediná Alves. Proteção e defesa da saúde. Hucitec/Sobravima, São Paulo, 1999.

CRESPO, Patrício Gallegos. Sistema de Esgotos. 1. ed. Belo Horizonte: Editora UFMG - Departamento de Engenharia Sanitária e Ambiental da Escola de Engenharia da UFMG, 1997.

DACACH, Nelson Gandur. Saneamento Básico. Rio de Janeiro: Livros Técnicos e Científicos Editora S.A., 1984. 
DACACH, Nelson Gandur. Saneamento Básico, 3. ed. rev. Rio de Janeiro: Didática e Científica, 1990.

DI BERNARDO, Luiz; SABOGAL PAZ, Lyda Patricia. Seleção de tecnologias de tratamento de água. São Carlos: Editora LDIBE LTDA, 2008.

FAGUNDES. M. V. Moeda Forte. BIO - Revista brasileira de saneamento e meio ambiente. ABES, ano XIII, n. 26, Rio de Janeiro, 2003.

FUNASA. Manual de Saneamento. 3ạ Ed. Brasília: Fundação Nacional da Saúde, 2006.

FUNASA. Manual de Saneamento/Ministério da Saúde, Fundação Nacional de Saúde. 4aㅡ. Ed. Brasília: Funasa, 2015.

GLOSBE. Significado da palavra Sanu. Disponível em: < https://pt.glosbe.com>. Acesso em: 20 abr. 2017.

GUIMARÃES, A. J. A.; CARVALHO, D. F. de; SILVA, L. D. B. Saneamento básico. S. I., 2007,. Apostila do Instituto de Tecnologia/Departamento de Engenharia Universidade Federal Rural do Rio de Janeiro. Disponível em: < http://www.ufrrj.br/institutos/it/deng/leonardo/downloads/APOSTILA/Apostila\%2 0IT\%20179/Cap\%201.pdf>. Acesso em: 07 mai. 2017. 